\title{
CHUMBO E CÁDMIO DETECTADOS EM ALIMENTOS VEGETAIS E GRAMÍNEAS NO MUNICÍPIO DE SANTO AMARO-BAHIA
}

\author{
Gustavo Alonso Muñoz Magna*, Sandro Lemos Machado, Roberto Bagattini Portella e Miriam de Fátima Carvalho \\ Departamento de Ciência e Tecnologia dos Materiais, Escola Politécnica, Universidade Federal da Bahia, 40210-630 Salvador - \\ BA, Brasil
}

Recebido em 16/10/12; aceito em 24/2/13; publicado na web em 15/4/13

\begin{abstract}
LEAD AND CADMIUM DETECTED IN PLANT FOODS AND GRASSES IN SANTO AMARO, BAHIA. This study evaluated the level of the metals $\mathrm{Pb} \mathrm{mg} \mathrm{kg}{ }^{-1}$ and $\mathrm{Cd} \mathrm{mg} \mathrm{kg}{ }^{-1}$ found in plant species and the contribution of the levels detected in contaminated soils located in the urban area of the city of Santo Amaro, Bahia. Levels were determined by graphite furnace and flame atomic absorption spectrometry. The results showed the presence of $\mathrm{Pb}$ and $\mathrm{Cd}$ in plant species at levels ranging from 0.18 to $118.2 \mathrm{mg} \mathrm{kg}^{-1}$ and 0.04 to $7.29 \mathrm{mg} \mathrm{kg}^{-1}$, respectively. The concentration values obtained varied according to the plant species and were not strongly influenced by the concentration values detected in the soil.
\end{abstract}

Keywords: metals; soil contamination; vegetables.

\section{INTRODUÇÃO}

Os metais são considerados uma das maiores fontes de poluição do solo. Elementos tais como cobre $(\mathrm{Cu})$, níquel $(\mathrm{Ni})$, cádmio $(\mathrm{Cd})$, zinco $(\mathrm{Zn})$, cromo $(\mathrm{Cr})$ e chumbo $(\mathrm{Pb})$ desempenham um papel importante na contaminação deste compartimento ambiental. ${ }^{1,2}$ Porém, vale ressaltar que, embora possam ser tóxicos em doses elevadas, elementos tais como $\mathrm{Cu}, \mathrm{Zn}$ e cobalto (Co) desempenham um importante papel ecológico, sendo essenciais para o crescimento e desenvolvimento de plantas, animais e seres humanos. Ao contrário, elementos tais como $\mathrm{Cd}, \mathrm{Pb}$ e arsênio (As) não tem uma função biológica conhecida e podem exercer efeitos deletérios sobre vários componentes da biosfera quando são concentrados a valores acima de seus níveis considerados de referência. ${ }^{1,3-5}$

Ao contrário dos contaminantes orgânicos, os metais não são degradáveis e, apesar de apresentar alguma mobilidade no meio ambiente, a contaminação por estes elementos é relativamente estável ao longo do tempo. ${ }^{2} \mathrm{O}$ solo acumula e concentra os metais, devido a sua capacidade de retenção principalmente nas camadas superficiais e que correspondem à parte biologicamente mais ativa do solo. ${ }^{4}$ Desta forma, os metais presentes nestas camadas podem estar facilmente acessíveis aos vegetais cultivados em áreas contaminadas e esta disponibilidade é uma função dos próprios valores de concentração de metais no solo, além de outros fatores tais como as características físico-químicas do solo e a afinidade das espécies vegetais. Esses elementos podem expressar seu potencial poluente quando são absorvidos pelas plantas, podendo assim ser transferidos através da cadeia alimentar atingindo os seres humanos. O chumbo é considerado o metal poluente mais abundante no solo. ${ }^{6}$ No caso do cádmio, corresponde a um dos metais mais tóxicos, exibindo efeitos nocivos na atividade biológica do solo, no metabolismo de plantas e também na saúde humana. ${ }^{5}$ É por esta razão que a Organização Mundial da Saúde (OMS), através do comitê codex alimentar, estabelece limites para $\mathrm{Pb}$ e $\mathrm{Cd}$ presentes em vegetais. Para $\mathrm{Pb}$ os valores variam na faixa de $0,1-0,3 \mathrm{mg} \mathrm{kg}^{-1}$ e no caso do $\mathrm{Cd}$ os valores se estabelecem na faixa de $0,05-0,2 \mathrm{mg} \mathrm{kg}^{-1}$.

O objetivo deste trabalho foi avaliar o atual conteúdo dos metais $\mathrm{Pb}$ e $\mathrm{Cd}$ detectados em alimentos vegetais e gramíneas cultivadas em

*e-mail: ingmag@gmail.com solos contaminados da área urbana da cidade de Santo Amaro-BA e a contribuição dos teores presentes no solo para as plantas mediante a determinação dos fatores de transferência solo-planta.

\section{Disponibilidade e absorção de metais pelas plantas}

Os metais provenientes de fontes antropogênicas entram no ambiente e seguem os ciclos biogeoquímicos normais no solo. ${ }^{7} \mathrm{Da}$ mesma forma, a persistência dos contaminantes no solo é muito mais longa em comparação com outros compartimentos ambientais e a contaminação do solo especificamente por metais parece ser permanente. ${ }^{5}$

Todas as espécies vegetais respondem ao incremento na concentração de metais no solo, sejam estes nutrientes essenciais ou não e a absorção e posterior acumulação dependem em primeira instância do movimento dos metais desde a solução no solo até as raízes das plantas. ${ }^{89}$ A concentração de metais nas espécies vegetais é diferente, entre outros aspectos, em função da disponibilidade do elemento no solo (biodisponibilidade), da espécie vegetal e da parte do vegetal que é analisada. ${ }^{5}$

A absorção de metais pelas plantas cultivadas em solos contaminados tem sido estudada de forma considerável. Todos os resultados têm mostrado que níveis elevados de metais no solo podem conduzir a uma maior absorção pelas plantas. Porém, não há geralmente uma forte relação entre as concentrações no solo e nas espécies vegetais, devido ao fato de que diversos fatores tais como tipo de solo, a solubilidade dos metais no mesmo, a distribuição do metal nos diferentes tecidos da planta e características específicas da espécie vegetal, interferem na transmissão da contaminação solo-vegetal. ${ }^{10}$ Neste contexto, um elevado teor de contaminantes no solo nem sempre está relacionado com um alto conteúdo nos vegetais, porém diversos estudos expõem que a acumulação no caso especifico do $\mathrm{Pb}$ nas plantas acontece somente com altas concentrações do metal no solo. ${ }^{11,12}$

Da mesma forma, a absorção de metais pelas plantas está condicionada pela mobilidade dos contaminantes no solo e pela especiação do metal, além da característica especifica de afinidade de cada espécie vegetal. Uma vez absorvidos, os metais tendem a acumular-se nas raízes, as quais são os primeiros órgãos vegetais atingidos pela contaminação. ${ }^{13}$ Isto acontece porque a rizosfera (área com tamanho de 1-2 mm, localizada entre as raízes das plantas e o solo) recebe grandes quantidades de matéria orgânica que abriga uma intensa 
atividade microbiológica e bioquímica, permitindo a mobilidade de alguns dos metais para as raízes, os quais estão adsorvidos no solo, por processos de acidificação, mudança redox ou formação de complexos orgânicos. Além do anterior, as condições climáticas são outro fator que pode influenciar a absorção de metais pelas plantas, devido aos fluxos de águas e temperatura. ${ }^{5}$

As diferenças na captação dos íons metálicos entre as espécies de plantas e culturas são geneticamente controladas e influenciadas por vários fatores, entre os quais se destacam a área superficial das raízes, a capacidade de troca catiônica, a exsudação das mesmas e a taxa de evapotranspiração. ${ }^{14}$

Por outro lado, a presença de altos conteúdos de outros metais tais como $\mathrm{Cu}, \mathrm{Ni}, \mathrm{Zn}, \mathrm{Se}, \mathrm{Mn}$ e $\mathrm{P}$ podem reduzir a absorção dos metais pelas espécies vegetais. Relações antagônicas e sinérgicas são descritas destacando o efeito antagônico que exerce o Zn no solo sobre a absorção de Cd pelas plantas. ${ }^{5}$

De maneira mais específica, os fatores que afetam a quantidade de metal absorvido por uma planta esta condicionada por: (i) as concentrações e especiação dos metais na solução do solo; (ii) movimentos dos metais, desde o solo até a superfície das raízes; (iii) transporte dos metais desde a superfície das raízes até o interior destas e (iv) translocação desde as raízes, até outras partes da planta. ${ }^{14}$

A absorção de metais, pelas raízes das plantas, pode ser produzida por processos passivos (não metabólica) e ativos (metabólicos). A absorção passiva implica a difusão de íons presentes na solução do solo dentro das endodermes das raízes. Por outro lado, a absorção ativa tem lugar junto com o gradiente de concentração, requerendo energia metabólica. Porém, os mecanismos parecem diferir entre os metais, por exemplo, a absorção de $\mathrm{Pb}$ é geralmente considerada como passiva, enquanto que a de $\mathrm{Cu}$, Mo e $\mathrm{Zn}$ pode ser considerada uma absorção ativa metabólica, ou uma combinação de ambas. ${ }^{14}$

Em resumo, pode-se dizer que a relação metal-solo-planta é multifatorial e dependerá não somente da sensibilidade intrínseca das espécies vegetais, senão também de diversos fatores externos, tais como a intensidade (concentração e duração) da exposição, o tipo de metal envolvido, a forma química deste (especiação) e as características físico-químicas do solo impactado.,

\section{Fatores de transferência solo-planta}

Uma aproximação empírica que permite avaliar a transferência dos metais desde o solo para as espécies vegetais corresponde ao cálculo dos fatores de transferência solo-planta $\left(\mathrm{FT}_{\text {solo-planta }}\right)$. Os FT solo-planta relacionam a quantidade total ou parcial de um elemento químico presente na espécie vegetal analisada ou parte dela com seu respectivo conteúdo total no solo. ${ }^{15}$ A relação é definida pela equação:

$$
\mathrm{FT}_{\text {solo-planta }}=\mathrm{C}_{\text {planta }} / \mathrm{C}_{\text {total- solo }}
$$

onde: $\mathrm{FT}_{\text {solo-planta }}$ : fator de transferência solo-planta; $\mathrm{C}_{\text {planta }}$ : concentração do metal na planta ou parte dela $\left(\mathrm{mg} \mathrm{kg}^{-1}\right) ; \mathrm{C}_{\text {total-solo }}$ : concentração total do metal no solo $\left(\mathrm{mg} \mathrm{kg}^{-1}\right)$.

Os fatores de transferência solo-planta são calculados mediante o quociente da concentração total do metal presente na espécie vegetal ou parte dela e o conteúdo total do metal no solo. A anterior definição assume que a relação entre ambas variáveis é linear e constante. Porém, diversos estudos expõem que esta relação não tem porque ser linear, podendo ser pontual no tempo e espaço. ${ }^{15} \mathrm{Com}$ respeito à sua interpretação, um fator de transferência elevado expõe uma débil retenção dos contaminantes no solo e a capacidade de absorção dos metais pela espécie vegetal analisada. ${ }^{16}$ Valores de fatores de transferência para $\mathrm{Pb}$ encontram-se na faixa $0,01-0,1$ e no caso do $\mathrm{Cd}$ entre $1-10 .{ }^{14}$ Outros estudos expõem fatores de transferência típicos ou considerados de referência para os metais $\mathrm{Pb}$ e $\mathrm{Cd}$ menores aos reportados anteriormente, os quais estão nas faixas 0,0-0,9 e 0,0-2,7 respectivamente. ${ }^{17}$

\section{O caso do passivo ambiental da COBRAC}

O município de Santo Amaro, localizado no Recôncavo Baiano, a $72 \mathrm{~km}$ de Salvador, continua sendo atingido pela contaminação remanescente causada pelo passivo ambiental da Companhia Brasileira de Chumbo (COBRAC), condição que começou em 1956 quando a metalúrgica foi instalada na cidade e sendo mais intenso entre as décadas de 1960 e $1970 .{ }^{17}$

O processo de beneficiamento do chumbo baseava-se na obtenção do óxido de chumbo $(\mathrm{PbO})$ por meio de ustulação oxidante da galena ou do sulfeto de chumbo $(\mathrm{PbS})$, seguida das operações de sinterização e redução do óxido de chumbo a $\mathrm{Pb}$ metálico. O processo tem, como subproduto, escórias que contêm até $4 \%$ em peso de $\mathrm{PbO}$ e traços de cádmio $(\mathrm{Cd})$, antimônio (Sb) e arsênio (As), entre outros metais. ${ }^{18}$

Por falta de conhecimento, gerenciamento inadequado dos resíduos e regulamentações ineficazes na época da operação da fábrica, a escória obtida como subproduto do processo foi utilizada e disposta, pelo próprio poder público, sob diversas formas durante o período de operação da fábrica, como na pavimentação das ruas do centro da cidade, exemplo seguido por diversos moradores, que utilizaram a escória nos quintais de suas casas e pátios de escola.

Estudos realizados na escória demonstram que esta corresponde a um resíduo perigoso, conforme NBR 10.004/1987. ${ }^{19}$ Esta situação provocou a contaminação de vários compartimentos ambientais, condição que foi reportada no ano 2003 pela Fundação Nacional de Saúde (FUNASA) e que identificou o município de Santo Amaro como uma das áreas prioritárias para a vigilância ambiental relacionada com solos contaminados no Brasil.

Conteúdos de $\mathrm{Pb}$ e $\mathrm{Cd}$ no solo das áreas impactadas pelo passivo ambiental da COBRAC (quintais e área externa da fábrica) foram expostos em um estudo realizado no ano $2010 .{ }^{20}$ Os resultados confirmam a persistência da contaminação por metais em solos de quintais do município e na área externa da fábrica em um raio de 4,0 Km aproximadamente. Das análises realizadas em 223 amostras de solo superficial da Rua Rui Barbosa, aproximadamente $80 \%$ apresentaram valores acima do limite de intervenção para chumbo (300 $\mathrm{mg} \mathrm{kg}^{-1}$ ) para áreas residenciais e 50\% apresentaram concentrações acima do limite de intervenção industrial $\left(900 \mathrm{mg} \mathrm{kg}^{-1}\right)$ estabelecido pela resolução CONAMA $\mathrm{N}^{\circ} 420 / 2009 .{ }^{21} \mathrm{O}$ valor da concentração média obtida para chumbo foi de $1316,24 \mathrm{mg} \mathrm{kg}^{-1}$ e para cádmio o valor correspondeu a 7,4 $\mathrm{mg} \mathrm{kg}^{-1}$. Já na área externa da fábrica foram detectados valores médios para $\mathrm{Pb}$ e $\mathrm{Cd}$ de 307,58 e $4,93 \mathrm{mg} \mathrm{kg}^{-1}$ respectivamente.

\section{PARTE EXPERIMENTAL}

\section{Amostragem}

Na presente pesquisa a área de estudo compreendeu três subaéreas, a saber: i) quintais com presença de hortas e plantas com frutas comestíveis da Rua Rui Barbosa e Sacramento, identificados no projeto Purifica (2002) como áreas prioritárias de investigação para mitigação do problema de contaminação do solo; ii) a área geográfica situada no entorno da ex fábrica e vinculada à dispersão das antigas emissões atmosféricas da mesma e iii) a localidade de Oliveira dos Campinhos, localizada a cerca de $20 \mathrm{Km}$ do centro de Santo Amaro, que foi escolhida como área de referência.

Os alimentos vegetais analisados foram determinados mediante os critérios de presença e abundância nos quintais, além do potencial 
consumo pela população. Para esta seleção foi necessária a elaboração e aplicação de questionários padronizados como ferramenta de pesquisa, abordando dados sócio-demográficos e um inquérito de presença de espécies vegetais em quintais. Os dados obtidos foram quantificados determinando as frequências de ocorrência de cada vegetal encontrado no total dos quintais estudados. Os alimentos vegetais selecionados corresponderam às espécies de frutas e ervas, acerola (Malpichia glabral), aroeira (Schinus molle), alumã (Veronia bahiensis tol), banana (Musa paradisica), boldo do Chile (Peumus boldus molina), capim santo (Cybopogon citratus), cana (Arundo donax. L), cidreira (Lippia alba), goiaba (Psidum cattleianum), limão (Citrus limonum), laranja (Citrus aurantium), manga (Mangifera indica) e mandioca (Manihot esculenta).

Da mesma forma, as gramíneas objeto de estudo foram selecionadas mediante os critérios de presença e abundância nos pontos vinculados à dispersão das antigas emissões atmosféricas da fábrica, estas corresponderam ao capim de burro (Capim elieusine indica) e capim braquiária (Capim brachiaria decumbens). Na localidade de Oliveira dos Campinhos foram selecionadas, segundo disponibilidade nos quintais, as espécies vegetais banana, limão, aroeira, cana, cidreira, capim santo, alumã e boldo do Chile.

Foi necessária a realização de duas campanhas de coletas: a primeira no mês de Junho de 2009 e a segunda, de forma complementar, em Agosto de 2010, com o intuito de melhorar a quantidade de amostras e obter maior evidência em relação à presumível contaminação nos vegetais. Em ambas as campanhas foram colhidos um mínimo de três frutos para cada espécie vegetal segundo a disponibilidade no local.

A amostragem foi realizada manualmente através da coleta no local de frutas, ervas e gramíneas. Da mesma forma, foram coletadas amostras de solo superficial $(20 \mathrm{~cm})$ nos mesmos pontos onde se desenvolvem as espécies vegetais avaliadas. As amostras de vegetais e solo coletadas em ambas as campanhas foram acondicionadas em sacos plásticos fechados e devidamente etiquetados para seu posterior envio para o laboratório do Centro de Pesquisa e Desenvolvimento da Bahia (CEPED), localizado no município de Camaçari-BA (CEPED), e o laboratório em Meio Ambiente da Universidade Católica de Salvador (LEMA/UCSAL), localizado no município de Salvador-BA, respectivamente. Já em ambos os laboratórios, as amostras foram congeladas até o momento da realização das análises.

\section{Determinação do conteúdo de $\mathrm{Pb}$ e $\mathrm{Cd}$ em alimentos vegetais e gramíneas}

A primeira campanha envolveu um total de 65 ensaios para a mensuração dos conteúdos dos metais $\mathrm{Pb}$ e $\mathrm{Cd}$, obtendo os teores em frutas e ervas cultivadas nos quintais da Rua Rui Barbosa. Para a determinação dos teores dos contaminantes de interesse nas gramíneas identificadas na área entorno da fábrica realizaram-se 33 ensaios. A determinação das concentrações dos metais foi realizada mediante o seguinte procedimento apresentado de forma simplificada: (1) lavagem das amostras com água deionizada, (2) secagem a $60{ }^{\circ} \mathrm{C}$ até peso constante, (3) moagem, (4) aquecimento por micro-ondas e digestão com ácido nítrico $\left(\mathrm{HNO}_{3}\right)$ em sistema fechado, finalizando com a (5) quantificação das concentrações com emprego da técnica de FAAS. Os ensaios foram realizados em amostras de polpa dos frutos, folhas e/ou caule segundo a espécie analisada, todas correspondendo às partes comestíveis dos vegetais coletados.

Já a segunda campanha envolveu um total de 42 ensaios em frutas e ervas cultivadas nos quintais da Rua Rui Barbosa e Rua Sacramento, localizadas nos arredores da fábrica. Para mensurar os conteúdos dos contaminantes nas espécies vegetais foi necessário dividir o processo em três etapas, (1) acondicionamento e preparo de amostras, (2) abertura das amostras e (3) leitura das concentrações dos contaminantes de interesse. $\mathrm{O}$ processo similar ao da primeira campanha diferençou-se principalmente na etapa de secagem (mediante estufa a uma temperatura de $65^{\circ} \mathrm{C}$ até peso constante), aquecimento mediante bloco digestor e quantificação com emprego da técnica de GFAAS.

Importante é destacar que a mudança da técnica de quantificação dos metais na segunda campanha em relação à primeira teve como objetivo melhorar o limite de detecção do método devido ao alto número de ensaios que apresentaram conteúdos abaixo do mesmo e que dificultaram a comparação com os valores limites dos contaminantes em vegetais estabelecidos pela OMS. Na Tabela 1 se apresenta um resumo das características de ambas as campanhas para vegetais.

\section{Digestão das amostras de vegetais}

$\mathrm{O}$ método de digestão das amostras foi baseado no manual de preparação de amostras do digestor por micro-ondas e conforme a metodologia para alfafa. Anterior à digestão pesou-se aproximadamente $0,5 \mathrm{~g}$ da amostra para bomba de teflon, adicionou-se $10 \mathrm{~mL}$ de $\mathrm{HNO}_{3} 65 \%$ Merck ${ }^{\circledR}$, aqueceu-se mediante bloco digestor a $121{ }^{\circ} \mathrm{C}$ por 2 horas. Posteriormente a amostra foi esfriada, filtrada em papel faixa branca e levada para balão volumétrico de $50 \mathrm{~mL}$ com água deionizada. Já na segunda campanha, pesou-se $0,1 \mathrm{~g}$ do material, colocou-se o material em tubos digestores adicionando $2 \mathrm{~mL}$ de $\mathrm{HNO}_{3} 65 \%$ Merck ${ }^{\circledR}$ e deixou-se em capela por 24 horas. Aqueceu-se a solução a $100{ }^{\circ} \mathrm{C}$ mediante bloco digestor por 1 hora. Repetiu-se o procedimento com tampa semiaberta durante $30 \mathrm{~min}$. Finalizou-se o processo aquecendo novamente a amostra por mais uma hora a uma temperatura de $140{ }^{\circ} \mathrm{C}$. Foram preparadas duplicatas do material a mensurar a cada cinco amostras para obter um controle de qualidade na determinação. Todo o processo para a determinação dos contaminantes de interesse incluíram as etapas de descontaminação e lavagem dos materiais utilizados previamente às análises com água (Milli-Q®) e ácido nítrico $10 \%$.

\section{Procedimento analítico}

A amostra digerida foi diluída para $10 \mathrm{~mL}$ com água deionizada e posteriormente colocada nos coletores de $2 \mathrm{~mL}$ para o amostrador automático. Cabe destacar que as amostras que se apresentaram muito concentradas foram diluídas 10 vezes com água desionizada. Nos ensaios da primeira campanha foi utilizado um espectrômetro de absorção atômica modelo AAnalyst 100, marca Perkin Elmer, software Winlab. Já nos ensaios da segunda campanha foram realizados mediante um espectrofotômetro de absorção atômica com forno de grafite modelo GTA 110, marca Varian, com correção de background. As leituras das amostras foram realizadas mediante o software Spectraa 220Z. O equipamento foi programado para injetar três vezes cada solução de análise e o valor de concentração considerado correspondeu ao valor médio das leituras realizadas. Em relação à exatidão do método, esta foi avaliada de acordo com o material

Tabela 1. Resumo dos antecedentes de ambas as campanhas para a determinação de metais em vegetais

\begin{tabular}{|c|c|c|c|c|c|c|}
\hline Campanha & Período & Local & $\begin{array}{c}\text { Número de } \\
\text { ensaios }\end{array}$ & $\begin{array}{l}\text { Método de } \\
\text { digestão }\end{array}$ & $\begin{array}{c}\text { Método de } \\
\text { Quantificação }\end{array}$ & Laboratório \\
\hline Primeira & Junho 2009 & Rua Rui Barbosa, Santo Amaro-BA & 65 & Parcial & FAAS & CEPED \\
\hline Segunda & Agosto 2010 & Rua Rui Barbosa e Sacramento, Santo Amaro-BA & 42 & Parcial & GFAAS & LEMA/UCSAL \\
\hline
\end{tabular}


de referência certificado pelo National Institute of Standard and Technology (NIST) folhas de maçã (NIST SRM 1515 Apple leaves) em triplicata para cada batelada de amostras.

\section{Determinação do conteúdo de $\mathrm{Pb}$ e $\mathrm{Cd}$ no solo}

\section{Preparação das amostras}

As amostras de solo da primeira campanha proveniente dos quintais e área externa da fábrica foram homogeneizadas para posterior retirada de uma alíquota de $200 \mathrm{~g}$. O material foi acondicionado em sacos plásticos devidamente identificados e enviados para laboratório (CEPED). Ao chegar ao laboratório a amostra foi novamente homogenizada, quarteada, secada em estufa a $40{ }^{\circ} \mathrm{C}$ e moída até a obtenção de $10 \mathrm{~g}$ de material passando pela peneira com abertura de $0,150 \mathrm{~mm}$ (80 mesh). Posteriormente o material foi encaminhado para análise. O preparo das amostras de solo coletado na segunda campanha diferençou-se especificamente na etapa de secagem, a qual foi feita ao ar livre até peso constante. Cabe destacar que as amostras de solo desta campanha foram preparadas e acondicionas pelo LEMA/UCSAL.

\section{Digestão das amostras e quantificação dos contaminantes}

A digestão das amostras de solo da primeira campanha foi realizada inicialmente mediante os métodos de digestão parcial e total, de forma a se analisar a biodisponibilidade dos elementos de interesse.

O método de digestão parcial foi feito conforme a Norma ASTM 1971/95. Neste procedimento uma alíquota de $1,0 \mathrm{~g}$ foi digerida por micro-ondas em temperatura de $121^{\circ} \mathrm{C}$ por 30 minutos com os ácidos nítrico $\left(\mathrm{HNO}_{3}\right)$ e clorídrico $(\mathrm{HCl})$, sendo posteriormente filtrada e levada para volume de $100 \mathrm{~mL}$ com água deionizada. Já o método de digestão total foi realizado conforme Norma US-EPA 3052. A amostra foi digerida por micro-ondas em temperatura de $180^{\circ} \mathrm{C}$ por $30 \mathrm{~min}$ com os ácidos nítrico $\left(\mathrm{HNO}_{3}\right)$, clorídrico $(\mathrm{HCl})$ e fluorídrico $(\mathrm{HF})$, sendo posteriormente filtrada e levada para volume de $100 \mathrm{~mL}$ com água deionizada. As substâncias de interesse foram quantificadas por FAAS. Todos os ensaios para a determinação do conteúdo dos metais $\mathrm{Pb}$ e $\mathrm{Cd}$ da primeira campanha foram realizados pelo laboratório do CEPED.

Os resultados dos ensaios realizados mediante ambos os métodos (digestão parcial e total) se apresentaram idênticos, indicando que a digestão parcial foi capaz de remover todo o conteúdo dos metais de interesse da matriz de solo, sendo escolhido então o método de digestão parcial para a realização dos ensaios restantes de forma a diminuir o tempo para a execução dos ensaios em virtude da grande quantidade de amostras de solo a analisar.

A determinação dos metais do solo na segunda campanha foi realizada mediante a utilização de água régia $\left(\mathrm{HNO}_{3}\right.$ e $\left.\mathrm{HCl}\right)$ e digestão em bloco digestor a $100{ }^{\circ} \mathrm{C}$ durante 1 hora. $\mathrm{O}$ procedimento foi repetido com tampa semiaberta durante 30 minutos, finalizando o processo novamente por mais uma hora a uma temperatura de 140 ${ }^{\circ} \mathrm{C}$. Foram preparadas duplicatas do material a mensurar a cada cinco amostras, além da utilização de brancos de análises para obter um controle de qualidade na determinação dos metais. Os contaminantes foram determinados mediante a técnica de FAAS.

\section{Determinação dos fatores de transferência solo-planta (FT solo- planta)}

Para a determinação dos $\mathrm{FT}_{\text {solo-planta }}$ nas diferentes espécies vegetais utilizou-se a equação (1). Vale ressaltar que no caso dos $\mathrm{FT}_{\text {solo-planta }}$ para Cd empregou-se o valor do limite de detecção (como valor máximo) quando a concentração mensurada nos vegetais e no solo estava abaixo do limite de detecção do método utilizado. Os valores utilizados para o cálculo dos $\mathrm{FT}_{\text {solo-planta }}$ correspondem aos conteúdos médios determinados para cada espécie avaliada.

\section{RESULTADOS E DISCUSSÃO}

Dos 105 ensaios realizados para a determinação de $\mathrm{Pb}$ em vegetais cultivados nos quintais das Ruas Rui Barbosa e Sacramento, 63 $(60 \%)$ foram feitos em frutos e o restante em ervas utilizadas pela população. Já dos ensaios para a detecção de Cd (totalizando 103), 38 foram feitos em frutos e o restante em ervas. Os resultados indicam que os frutos analisados apresentam conteúdos de $\mathrm{Pb}$ na faixa de 0,18 $\mathrm{mg} \mathrm{kg}-1$ a $118,2 \mathrm{mg} \mathrm{kg}^{-1}$. Os maiores teores do contaminante foram detectados nas frutas acerola e laranja com valores de 118,2 e 117,3 $\mathrm{mg} \mathrm{kg}^{-1}$ respectivamente. Na Tabela 2 apresenta-se uma síntese dos resultados para ambos os contaminantes detectados nos alimentos vegetais analisados. Vale ressaltar que na Tabela 2 se apresentam teores dos contaminantes determinados por ambos os métodos (FAAS e GFAAS) e, portanto com limites de detecção diferentes, dependentes da massa da amostra utilizada na determinação.

Tabela 2. Conteúdos de chumbo e cádmio encontrados em espécies vegetais cultivadas nos quintais da Rua Rui Barbosa e Sacramento

\begin{tabular}{|c|c|c|c|c|c|c|c|c|c|c|c|c|c|}
\hline \multirow{2}{*}{\multicolumn{2}{|c|}{ Espécies vegetais }} & \multicolumn{6}{|c|}{$\mathrm{Pb}(\mathrm{mg} / \mathrm{kg})$} & \multicolumn{6}{|c|}{$\mathrm{Cd}(\mathrm{mg} / \mathrm{kg})$} \\
\hline & & Min & Max & Média & DP & $\mathrm{n}$ & $\mathrm{n}_{\mathrm{m}}$ & Min & $\operatorname{Max}$ & Média & DP & $\mathrm{n}$ & $\mathrm{n}_{\mathrm{m}}$ \\
\hline 1 & Banana (Musa paradisica) & 0,18 & 0,24 & 0,20 & 0,11 & 9 & 4 & 0,04 & 2,2 & 0,82 & 1,22 & 9 & 4 \\
\hline 2 & Acerola (Malpichia glabral) & 1,10 & 118,2 & 36,7 & 42,6 & 10 & 6 & 0,22 & 0,57 & 0,33 & 0,16 & 10 & 4 \\
\hline 3 & Manga (Mangifera indica) & 0,36 & 22,2 & 10,8 & 9,8 & 12 & 7 & 0,09 & 0,37 & 0,22 & 0,09 & 12 & 6 \\
\hline 4 & Goiaba (Psidum cattleianum) & $<4$ & 27,4 & $*$ & $*$ & 5 & $*$ & 0,11 & $<2$ & $*$ & $*$ & 5 & $*$ \\
\hline 5 & Limão (Citrus limonum) & 6,95 & 32,5 & 21,2 & 2,96 & 6 & 4 & 0,04 & 0,1 & 0,06 & 0,03 & 6 & 4 \\
\hline 6 & Aroeira (Schinus molle) & 1,49 & 44,8 & 14,8 & 14,0 & 11 & 8 & 0,46 & 0,79 & 0,62 & 0,18 & 11 & 4 \\
\hline 7 & Cana (Arundo donax. L) & 1,61 & $<4$ & $*$ & $*$ & 8 & $*$ & 1,66 & $<2$ & $*$ & $*$ & 8 & $*$ \\
\hline 8 & Cidreira (Lippia alba) & 1,26 & 32,3 & 16,8 & 12,3 & 10 & 8 & 0,25 & 4,95 & 1,35 & 2,01 & 10 & 5 \\
\hline 9 & Capim santo (Cybopogon citratus) & 13,1 & 23 & 16,7 & 6,3 & 8 & 4 & 0,1 & 6,68 & 2,84 & 3,42 & 8 & 4 \\
\hline 10 & Alumã (Veronia bahiensis tol) & 6,58 & 51,7 & 24,9 & 7,1 & 9 & 4 & 0,75 & 7,39 & 3,21 & 3,63 & 9 & 4 \\
\hline 11 & Boldo do Chile (Peumus boldus molina) & 14,6 & 19 & 16,8 & 3,1 & 4 & 2 & $<5$ & $<5$ & $*$ & $*$ & 4 & $*$ \\
\hline 12 & Laranja (Citrus aurantium) & 0,47 & 117,3 & 39,9 & 40,4 & 11 & 6 & 0,08 & 0,15 & 0,12 & 0,04 & 9 & 4 \\
\hline \multirow[t]{2}{*}{13} & Mandioca (Manihot esculenta) & 10,7 & 23 & 16,8 & 8,7 & 4 & 4 & 0,61 & 1,25 & 0,93 & 0,45 & 2 & 2 \\
\hline & Resumo & 0,18 & 118,2 & 19,6 & 6,2 & 107 & 57 & $\mathbf{0 , 0 4}$ & 7,39 & 1,05 & 1,11 & 103 & 41 \\
\hline
\end{tabular}

*Valores indeterminados por estarem abaixo do limite de detecção do método empregado (FAAS). n: número de ensaios; DP: desvio padrão em função do número de ensaios; $\mathrm{n}_{\mathrm{m}}$ : número de amostras com resultados acima do limite de detecção utilizadas para o cálculo dos valores médios; ND: não determinado. No caso do boldo do Chile não foi quantificado o metal Cd mediante GFAAS. No caso do fruto Goiaba somente um valor apresento conteúdo mensurável (GFAAS). 
Tabela 3. Conteúdo de chumbo e cádmio encontrados em gramíneas da área de externa da fábrica

\begin{tabular}{|c|c|c|c|c|c|c|c|c|c|c|c|c|}
\hline \multirow{2}{*}{\multicolumn{2}{|c|}{ Espécies vegetais }} & \multicolumn{6}{|c|}{$\mathrm{Pb}\left(\mathrm{mg} \mathrm{kg}^{-1}\right)$} & \multicolumn{5}{|c|}{$\mathrm{Cd}\left(\mathrm{mg} \mathrm{kg}^{-1}\right)$} \\
\hline & & Min & Max & Média & DP & $\mathrm{n}$ & $\mathrm{n}_{\mathrm{m}}$ & Min & Max & Média & DP & $\mathrm{n}$ \\
\hline 1 & Capim de burro (Capim elieusine indica) & $<10$ & 820 & 253,3 & 332,3 & 9 & 5 & $<5$ & 7,9 & $*$ & $*$ & 9 \\
\hline 2 & Capim braquiária (Capim brachiaria decumbens) & $<10$ & 18,5 & 15,2 & 3,9 & 24 & 4 & $<5$ & $<5$ & $*$ & $*$ & 24 \\
\hline & Resumo & $<10$ & 820 & 134,4 & 168,1 & 33 & 9 & $<5$ & $<5$ & $*$ & $*$ & 33 \\
\hline
\end{tabular}

*Valores indeterminados por estarem abaixo do limite de detecção do método empregado (FAAS). n: número de ensaios; DP: desvio padrão em função do número de ensaios; $\mathrm{n}_{\mathrm{m}}$ : número de amostras com resultados acima do limite de detecção utilizadas para o cálculo dos valores médios.

Todos os frutos analisados expõem elevadas concentrações médias para $\mathrm{Pb}$, que superam amplamente o valor limite estabelecido pela OMS de $0,1 \mathrm{mg} \mathrm{kg}^{-1}$ para o contaminante em alimentos vegetais e os valores apresentados no estudo de Cunha \& Araújo no ano $2001^{22}$ para diversos vegetais cultivados em solos da área de estudo (faixa de 11,9 a $\left.15,2 \mathrm{mg} \mathrm{kg}^{-1}\right)$.

Para $\mathrm{Pb}$ em ervas, todas as espécies apresentaram conteúdos acima do valor estabelecido pela OMS para vegetais folhosos e ervas de $0,3 \mathrm{mg} \mathrm{kg}^{-1}$. Os teores foram estabelecidos na faixa de 1,26 a 51,7 $\mathrm{mg} \mathrm{kg}$. As concentrações de $\mathrm{Pb}$ detectadas nos alimentos vegetais cultivados nos quintais da área de estudo expõem a contaminação das espécies avaliadas.

Para $\mathrm{Cd}$ presente nas frutas analisadas, os teores mensurados encontram-se na faixa de $0,04 \mathrm{mg} \mathrm{kg}^{-1}$ a $7,39 \mathrm{mg} \mathrm{kg}^{-1}$. As maiores concentrações de $\mathrm{Cd}$ foram detectadas nas ervas alumã (7,39 $\left.\mathrm{mg} \mathrm{kg}^{-1}\right)$ e capim santo $\left(6,68 \mathrm{mg} \mathrm{kg}^{-1}\right)$. Todos os frutos analisados expõem concentrações médias de $\mathrm{Cd}$ acima do valor limite estabelecido pela OMS de 0,05 $\mathrm{mg} \mathrm{kg}^{-1}$.

Geralmente o conteúdo de metais nos vegetais decresce na seguinte ordem; raízes $>$ caule $>$ folhas $>$ fruto $>$ sementes,${ }^{23}$ por isso a análise das outras partes das plantas resulta interessante dependendo do objetivo e tipo de estudo. No presente trabalho concentrou-se apenas nas partes comestíveis dos vegetais, já que um dos objetivos principais do mesmo foi avaliar também as doses de ingestão de metais pela população em função do consumo de vegetais presumivelmente contaminados.

Já as concentrações dos contaminantes avaliadas por grupos se apresentaram para frutas com um conteúdo médio de $\mathrm{Pb}$ de $20,9 \mathrm{mg} \mathrm{kg}^{-1}$ e desvio padrão (DP) de $15,2 \mathrm{mg} \mathrm{kg}^{-1}$. No caso das ervas, o conteúdo médio determinado foi de $18,0 \mathrm{mg} \mathrm{kg}^{-1}$ e desvio padrão de 3,9 $\mathrm{mg} \mathrm{kg}^{-1}$. Para Cd em frutas, o teor médio foi determinado em $0,37 \mathrm{mg} \mathrm{kg}^{-1}$ e desvio padrão de $0,52 \mathrm{mg} \mathrm{kg}^{-1}$. Nas ervas, a concentração média se estabeleceu em $1,91 \mathrm{mg} \mathrm{kg}^{-1}$ e desvio padrão de 2,13 $\mathrm{mg} \mathrm{kg}^{-1}$. Em ambos os grupos os valores médios obtidos $\mathrm{de} \mathrm{Pb}$ e $\mathrm{Cd}$ se apresentam acima dos valores limites recomendados pela OMS.

Da mesma forma, os resultados obtidos para as espécies de gramíneas da área vinculada às antigas emissões atmosféricas da fábrica são apresentados na Tabela 3. Os resultados observados indicam que as espécies capim de burro e capim braquiária apresentaram conteúdos elevados de $\mathrm{Pb}$ e $\mathrm{Cd}$.

No caso da primeira espécie, o teor médio de $\mathrm{Pb}$ foi de $253,3 \mathrm{mg}$ $\mathrm{kg}^{-1}$ com um desvio padrão (DP) de $332,3 \mathrm{mg} \mathrm{kg}^{-1}$ e um conteúdo máximo (máx) de $820 \mathrm{mg} \mathrm{kg}^{-1}$. Dos nove ensaios realizados nessa espécie, quatro apresentam um conteúdo abaixo do limite de detecção para $\mathrm{Pb}$. No caso do Cd, observou-se somente um ensaio com conteúdo mensurável do metal com um valor de $7,9 \mathrm{mg} \mathrm{kg}^{-1}$. Por outro lado, a espécie capim braquiária apresentou um teor máximo de 18,5 $\mathrm{mg} \mathrm{kg}^{-1}$ para $\mathrm{Pb}$ e um valor mínimo abaixo do limite de detecção do método $\left(<5 \mathrm{mg} \mathrm{kg}^{-1}\right)$ para $\mathrm{Cd}$. Todas as espécies que apresentaram conteúdos mensuráveis dos contaminantes expõem concentrações maiores em comparação aos valores de referência. ${ }^{5,24}$
Comparando-se os resultados obtidos neste trabalho com os resultados expostos por Costa no ano 2001 para gramíneas na área de estudo, pode se observar na Tabela 4 que em ambas as campanhas se apresentam conteúdos mensuráveis de $\mathrm{Pb}$ e $\mathrm{Cd}$ em espécies de gramíneas. Estes resultados confirmam a tendência na absorção de $\mathrm{Pb}$ e Cd neste tipo de espécie vegetal, o que concorda com o exposto por Kabata-Pendias \& Mukherjee ${ }^{23}$ os quais mencionam que as gramíneas apresentam maiores conteúdos de $\mathrm{Pb}$ em comparação com outras espécies vegetais.

Tabela 4. Conteúdo médio de chumbo e cádmio encontrados em gramíneas reportados por Costa (2001) e o Atual estudo (2011)

\begin{tabular}{ccc}
\hline Estudos & $\mathrm{Pb}\left(\mathrm{mg} \mathrm{kg}^{-1}\right)$ & $\mathrm{Cd}\left(\mathrm{mg} \mathrm{kg}^{-1}\right)$ \\
\hline Costa (2001) & 26,4 & 1,07 \\
Atual estudo (2011) & 134,4 & $<5$ \\
\hline
\end{tabular}

Na Tabela 4 observa-se também um aumento no teor médio de chumbo com o tempo, condição que pode ser explicada por fatores tais como proximidade da fábrica, espécie de gramínea analisada e estágio de desenvolvimento do vegetal no momento da análise, entre outros. Para $\mathrm{Cd}$ os valores se apresentaram similares com um conteúdo atual abaixo de $<5 \mathrm{mg} \mathrm{kg}^{-1}$.

Os conteúdos dos contaminantes $\mathrm{Pb}$ e $\mathrm{Cd}$ mensurados no solo de quintais da localidade de Oliveira dos Campinhos, área rural distante aproximadamente $20 \mathrm{~km}$ da cidade de Santo Amaro, se apresentaram abaixo do limite de detecção do método $\left(<10 \mathrm{mg} \mathrm{kg}^{-1}\right.$ para $\mathrm{Pb}$ e $<2 \mathrm{mg}$ $\mathrm{kg}^{-1}$ para Cd). Para os alimentos vegetais analisados nesta localidade todos os resultados, como esperado, expõem conteúdos abaixo do limite de detenção do método para ambos os metais.

Ao comparar os teores de $\mathrm{Pb}$ obtidos em alimentos vegetais cultivados em quintais da Rua Rui Barbosa e Sacramento e na localidade de Oliveira dos Campinhos, os valores médios das concentrações de $\mathrm{Pb}$ se apresentam sempre acima dos valores mensurados na área de referência. Para a fruta banana, esta análise ficou prejudicada devido ao elevado limite de detecção empregado em Oliveira dos Campinhos.

No caso do Cd detectado em alimentos vegetais cultivados em quintais da Rua Rui Barbosa e na localidade de Oliveira dos Campinhos, os valores de concentração obtidos estão sempre abaixo do limite de detecção do método no local de referência. Os resultados são expostos na Tabela 5 .

\section{Determinação dos fatores de transferência solo-planta}

Para avaliar a transferência e contribuição dos conteúdos dos contaminantes de interesse presentes no solo para as espécies vegetais foram determinados os $\mathrm{FT}_{\text {solo-planta }}$ Os $\mathrm{FT}_{\text {solo-planta }}$ determinados para frutas e ervas encontram-se na faixa de 0,000 a 0,040 e 0,12 a 2,2 para os contaminantes $\mathrm{Pb}$ e Cd, respectivamente. Os valores calculados se correspondem aos fatores considerados de referência. ${ }^{14,17}$ A síntese dos resultados é exposta na Tabela 6 . 
Tabela 5. Comparação dos conteúdos de chumbo encontrados em espécies vegetais cultivadas em quintais da Rua Rui Barbosa e Oliveira dos Campinhos

\begin{tabular}{|c|c|c|c|c|c|c|c|c|}
\hline \multirow[t]{2}{*}{ Espécies vegetais } & \multicolumn{4}{|c|}{ Quintais da Rua Rui Barbosa Pb (mg kg $\left.{ }^{-1}\right)$} & \multicolumn{4}{|c|}{ Quintais de Oliveira dos campinhos $\mathrm{Pb}\left(\mathrm{mg} \mathrm{kg}^{-1}\right)$} \\
\hline & Min & Max & Média & $\mathrm{n}$ & Min & Max & Média & $\mathrm{n}$ \\
\hline 1 Banana (Musa paradisica) & 0,18 & 0,24 & 0,20 & 9 & $<4$ & $<4$ & $*$ & 2 \\
\hline 2 Limão (Citrus limonum) & 6,95 & 32,5 & 21,2 & 6 & $<4$ & $<4$ & $*$ & 2 \\
\hline 3 Aroeira (Schinus molle) & 1,49 & 44,8 & 14,8 & 11 & $<10$ & $<10$ & * & 3 \\
\hline 4 Cana (Arundo donax. $l$ ) & 1,61 & $<4$ & $*$ & 8 & $<4$ & $<4$ & $*$ & 2 \\
\hline 5 Cidreira (Lippia alba) & 1,26 & 32,3 & 16,8 & 10 & $<10$ & $<10$ & $*$ & 2 \\
\hline 6 Capim santo (Cybopogon citratus) & 13,1 & 23,0 & 16,7 & 8 & $<10$ & $<10$ & $*$ & 2 \\
\hline 7 Alumã (Veronia bahiensis tol) & 6,58 & 51,7 & 24,9 & 9 & $<10$ & $<10$ & * & 2 \\
\hline 8 Boldo do Chile (Peumus boldus molina) & 14,6 & 19,0 & 16,8 & 4 & $<10$ & $<10$ & $*$ & 2 \\
\hline Resumo & 5,72 & 51,7 & 15,9 & 65 & $<4$ & $<\mathbf{1 0}$ & $*$ & 17 \\
\hline
\end{tabular}

*Valores indeterminados por estarem abaixo do limite de detecção do método empregado (FAAS). n: número de ensaios.

Tabela 6. Fatores de transferência solo-planta para $\mathrm{Pb}$ e $\mathrm{Cd}$ de espécies vegetais cultivadas em quintais com horta da Rua Rui Barbosa e Sacramento

\begin{tabular}{|c|c|c|c|c|c|c|c|c|c|}
\hline & \multirow{2}{*}{ Espécies vegetais } & \multicolumn{4}{|c|}{$\mathrm{Pb}$} & \multicolumn{4}{|c|}{$\mathrm{Cd}$} \\
\hline & & $\mathrm{C}_{\text {solo }}$ & $\mathrm{C}_{\text {vegetal }}$ & $\mathrm{n}$ & $\mathrm{FT}_{\text {solo-planta }}$ & $\mathrm{C}_{\text {solo }}$ & $\mathrm{C}_{\text {vegetal }}$ & $\mathrm{n}$ & $\mathrm{FT}_{\text {solo-planta }}$ \\
\hline 1 & Banana (Musa paradisica) & 1326,0 & 0,2 & 4 & 0,000 & 5 & 0,82 & 3 & 0,16 \\
\hline 2 & Acerola (Malpichia glabral) & 2441,0 & 29,5 & 5 & 0,012 & 16,5 & $<2$ & 2 & 0,12 \\
\hline 3 & Manga (Mangifera indica) & 190,8 & 7,88 & 4 & 0,041 & 1,90 & 0,28 & 3 & 0,14 \\
\hline 4 & Limão (Citrus limonum) & 2972,0 & 21,2 & 2 & 0,007 & 19,5 & 2,5 & 2 & 0,12 \\
\hline 5 & Aroeira (Schinus molle) & 1324,5 & 14,8 & 8 & 0,010 & $<5$ & 7,9 & 3 & 1,58 \\
\hline 6 & Cidreira (Lippia alba) & 2032,2 & 16,8 & 4 & 0,006 & 11,3 & $<5$ & 3 & 0,44 \\
\hline 7 & Capim santo (Cybopogon citratus) & 1285,0 & 16,7 & & 0,013 & 4,98 & 3,39 & 2 & 0,71 \\
\hline 8 & Alumã (Veronia bahiensis tol) & 4925,0 & 24,9 & 4 & 0,004 & 14,3 & $<5$ & 2 & 0,34 \\
\hline 9 & Boldo do Chile (Peumus boldus molina) & 2683,0 & 16,8 & 4 & 0,006 & $<5$ & 11 & 2 & 2,2 \\
\hline & Laranja (Citrus aurantium) & 929,8 & 39,9 & 5 & 0,040 & 15,19 & $<2$ & 2 & 0,13 \\
\hline & Mandioca (Manihot esculenta) & 744,5 & 16,8 & 4 & 0,002 & 5,13 & 0,93 & 2 & 0,18 \\
\hline
\end{tabular}

$\mathrm{C}_{\text {solo }}$ : concentração media do metal no solo $\left(\mathrm{mg} \mathrm{kg}^{-1}\right) ; \mathrm{C}_{\text {vegetal }}$ : concentração media do metal na planta $\left(\mathrm{mg} \mathrm{kg}^{-1}\right)$; n: número de ensaios; <5: Limite de detecção do método (FAAS), valor considerado como 5 para o cálculo dos fatores de transferência.

No caso do $\mathrm{Pb}$, os valores dos $\mathrm{FT}_{\text {solo-planta }}$ nas espécies vegetais avaliadas podem ser considerados como baixos e dentro das faixas de referência, indicando, desta forma, que elevadas concentrações de $\mathrm{Pb}$ no solo não são transferidas com intensidade aos vegetais analisados.

Entretanto, o comportamento observado para o Cd com relação aos fatores de transferência solo-planta foi inverso, um baixo teor de cádmio no solo (quando comparados aos teores de $\mathrm{Pb}$ no mesmo meio) apresentou conteúdos mensuráveis na maioria das espécies avaliadas. Isto pode indicar que a fração disponível ou biodisponível de $\mathrm{Cd}$ no solo pode corresponder a uma grande parte do conteúdo total de $\mathrm{Cd}$ neste meio e/ ou que estas espécies vegetais apresentam uma afinidade na absorção e acumulação deste contaminante na parte aérea, condição que é exposta nos fatores de transferência solo-planta que, quando comparados com os fatores solo-planta para $\mathrm{Pb}$, se apresentam maiores. A este respeito o genótipo da planta é um dos fatores que têm maior influência na absorção de cádmio, o que explicaria o fato da variabilidade entre as espécies. ${ }^{14}$ Além disso, o Cd apresenta uma maior mobilidade no solo em comparação com outros metais como o $\mathrm{Pb}$. Os resultados permitem determinar que teores elevados dos contaminantes de interesse no solo são transferidos e absorvidos em quantidades variáveis e de maneira específica pelas diferentes espécies vegetais.

No caso das gramíneas desenvolvidas na área externa da fábri$\mathrm{ca}$, os valores dos fatores de transferência solo-planta para $\mathrm{Pb}$ se apresentam na faixa de 0,02-0,13 em concordância com os valores apresentados como referência. ${ }^{17}$ Os valores para o $\mathrm{Cd}$ neste caso são menores que os expostos na literatura (1-10) indicando que um alto conteúdo de cádmio no solo não se relaciona proporcionalmente com o conteúdo presente nas gramíneas avaliadas. Os resultados são expostos na Tabela 7 .

Os $\mathrm{FT}_{\text {solo-planta }}$ estão baseados em uma relação linear entre o conteúdo dos elementos de interesse presentes nas espécies vegetais analisadas ou parte desta e seu respectivo conteúdo no solo. A relação entre o teor de $\mathrm{Pb}$ e $\mathrm{Cd}$ nas espécies vegetais avaliadas e seu respectivo conteúdo no solo é exposta para todas as espécies vegetais objeto de estudo na Figura 1. Vale ressaltar que, para construção do gráfico da Figura 1, somente foram consideradas as concentrações dos contaminantes acima dos limites de detecção dos métodos utilizados nos ensaios.

Pode-se observar uma débil associação entre as duas variáveis de estudo apresentando uma variação conjunta dos valores nos gráficos tanto para $\mathrm{Pb}$ como para $\mathrm{Cd}$. Ao aumentar o conteúdo do contaminante no solo, aumenta levemente a quantidade de $\mathrm{Pb}$ presente nas espécies vegetais. Situação inversa acontece com o $\mathrm{Cd}$, ao diminuir o teor do elemento no solo, aumenta levemente o teor nas espécies avaliadas. Apesar da existência desta associação entre as variáveis, o conteúdo no solo não explica de forma adequada os valores experimentais em 
Tabela 7. Fatores de transferência solo-planta para $\mathrm{Pb}$ e $\mathrm{Cd}$ encontrados em gramíneas da área externa da fábrica

\begin{tabular}{|c|c|c|c|c|c|c|c|c|c|}
\hline & \multirow{2}{*}{ Espécies vegetais } & \multicolumn{4}{|c|}{$\mathrm{Pb}$} & \multicolumn{4}{|c|}{$\mathrm{Cd}$} \\
\hline & & $\mathrm{C}_{\text {solo }}$ & $\mathrm{C}_{\text {vegetal }}$ & $\mathrm{n}$ & $\mathrm{FT}_{\text {solo-planta }}$ & $\mathrm{C}_{\text {solo }}$ & $\mathrm{C}_{\text {vegetal }}$ & $\mathrm{n}$ & $\mathrm{FT}_{\text {solo-planta }}$ \\
\hline 1 & Capim de burro (Capim elieusine indica) & 1889,5 & 253,3 & 5 & 0,13 & 14,2 & $<5$ & 5 & $<0,35$ \\
\hline 2 & Capim braquiária (Capim brachiaria decumbens) & 782,5 & 15,2 & 4 & 0,02 & 11,7 & $<5$ & 4 & $<0,43$ \\
\hline
\end{tabular}

$\mathrm{C}_{\text {solo }}$ : concentração media do metal no solo $\left(\mathrm{mg} \mathrm{kg}^{-1}\right) ; \mathrm{C}_{\text {vegetal }}$ : concentração media do metal na planta $\left(\mathrm{mg} \mathrm{kg}^{-1}\right)$; n: número de ensaios; $<5$ : Limite de detecção do método (FAAS), valor igual a 5 para o cálculo dos fatores de transferência solo-planta.
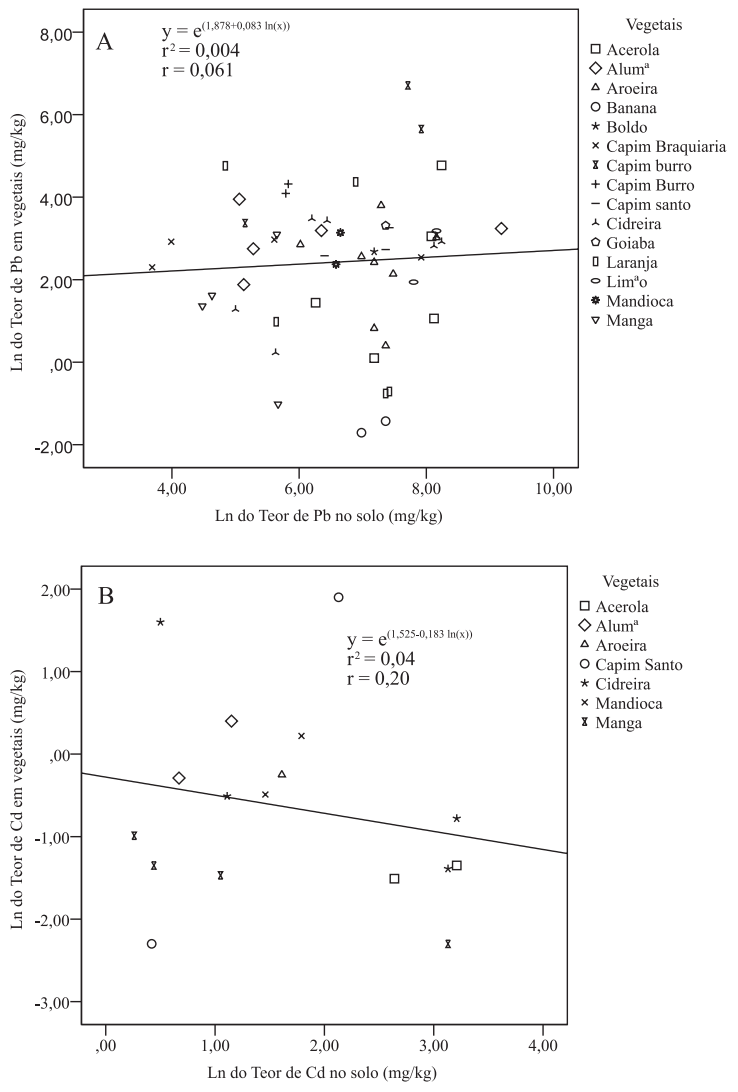

Figura 1. Teor de Pb em vegetais frente ao Teor de Pb no solo: (A), Teor de Cd em vegetais frente Teor de Cd no solo (B)

ambos os casos. A razão para este comportamento pode ser encontrada em função das diferenças entre as espécies vegetais avaliadas, o que gera um aumento da dispersão e prejudica a análise da relação. Desta forma, a presença de conteúdos de $\mathrm{Pb}$ e $\mathrm{Cd}$ nas espécies vegetais não depende única e exclusivamente do conteúdo presente no solo, indicando a multiplicidade de fatores envolvidos na transferência de metais do solo para as plantas.

São diversas variáveis que influenciam a transferência dos contaminantes de interesse desde o solo para as plantas, assim como existem diferentes mecanismos na sua posterior translocação e acumulação no interior destas. Isto é confirmado nos estudos realizados por Finster et al. ${ }^{25}$ os quais reportam a ausência de relação entre os conteúdos de $\mathrm{Pb}$ presentes na parte comestível de espécies vegetais e seu respectivo conteúdo no solo. Os autores, porém, apresentam uma relação linear entre o conteúdo de $\mathrm{Pb}$ em raízes e seu respectivo conteúdo no solo. Cabe destacar que a análise realizada está referida às espécies que apresentaram conteúdos mensuráveis dos contaminantes de interesse e nas quais foram calculados os fatores de transferência solo-planta.

Além da análise anterior, procedeu-se relacionar graficamente os fatores de transferência solo-planta para $\mathrm{Pb}$ e $\mathrm{Cd}$ com seus respectivos conteúdos no solo agrupados em ervas, gramíneas e frutas. As relações se apresentam nas Figuras 2 e 3.

Na Figura 2 pode se observar a variação conjunta dos valores dos $\mathrm{FT}_{\text {solo-planta }}$ em função dos logaritmos naturais dos conteúdos de $\mathrm{Pb}$ no solo, expondo a associação entre ambas as variáveis nos grupos
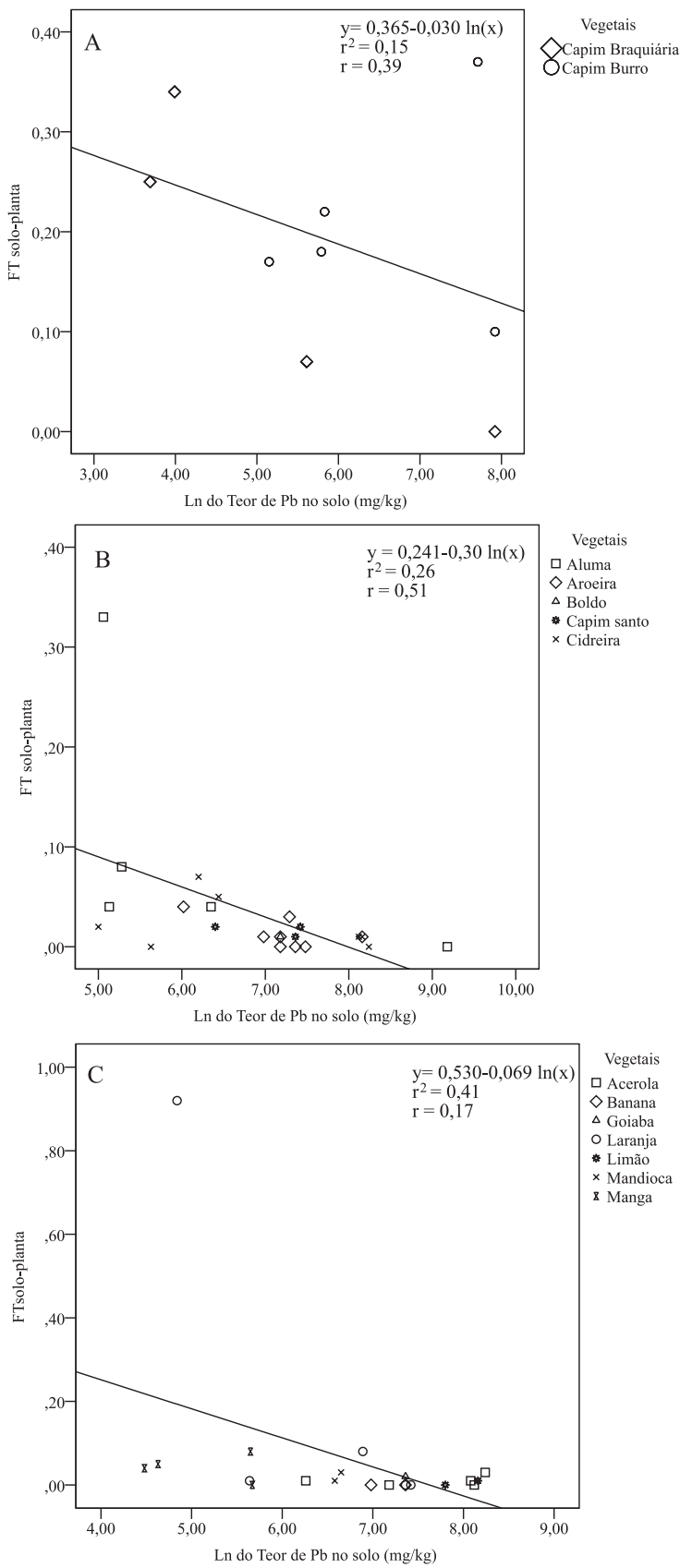

Figura 2. Fatores de transferência solo-planta para Pb em: (A) Gramíneas; (B) Ervas; (C) Frutas frente ao conteúdo total de Pb no solo 
avaliados. Nos gráficos podem se observar os diferentes graus da contribuição dos conteúdos de $\mathrm{Pb}$ presentes no solo para cada grupo de vegetais.

Na Figura 2 (A) e (B), pode-se apreciar claramente a diminuição dos fatores de transferência solo-planta com a concentração no solo, tendência observada para ervas e gramíneas. Já no gráfico (C) a intensidade desta associação é menor.

A mesma análise foi realizada para o contaminante $\mathrm{Cd}$ detectados em ervas e frutas. Os resultados são apresentados na Figura 3. Pode se observar a variação conjunta dos valores dos $\mathrm{FT}_{\text {solo-planta }}$ em função dos logaritmos naturais dos conteúdos de Cd no solo, expondo a associação entre ambas as variáveis nos grupos avaliados. Nos gráficos podem se observar os diferentes graus da contribuição dos conteúdos de $\mathrm{Cd}$ presentes no solo para cada grupo de vegetais.

Na Figura 3 (A) é possível observar o aumento dos valores dos fatores de transferência solo-planta com a diminuição dos teores de $\mathrm{Cd}$ detectados no solo. Esta relação observada entre as variáveis associadas é mais evidente em comparação a análise do contaminante $\mathrm{Pb}$ e seus respectivos fatores de transferência no mesmo grupo de vegetais (frutas).
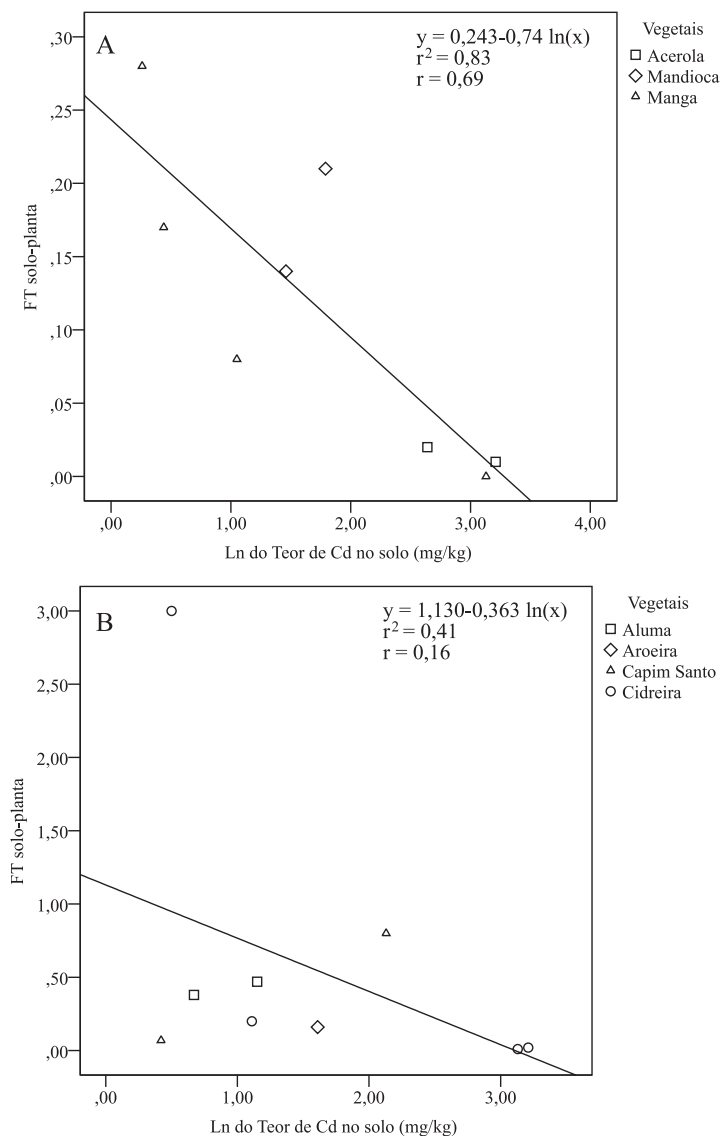

Figura 3. Fatores de transferência solo-planta para Cd em: (A) Frutas e (B) Ervas frente ao conteúdo total de Cd no solo

Já no gráfico (B) do grupo ervas, pode se apreciar uma tendência diferente em relação a frutas (relação menos intensa) dos fatores de transferência solo-planta com a concentração de Cd no solo. Ao comparar ambos os grupos para os contaminantes $\mathrm{Pb}$ e $\mathrm{Cd}$, pode-se observar uma tendência e associação mais pronunciada para o primeiro elemento $(\mathrm{Pb})$ em comparação ao segundo. Cabe destacar que a análise para o grupo de gramíneas não foi possível de ser realizada devido à ausência de valores de concentração de $\mathrm{Cd}$ acima do limite de detecção do método utilizado.

\section{CONCLUSÕES}

Uma quantidade considerável de quintais da Rua Rui Barbosa e Rua Sacramento possuem alimentos vegetais cultivados em solos com altos níveis de contaminação por $\mathrm{Pb}$ e Cd. Espécies tais como banana, manga e aroeira, entre outras, correspondem às mais abundantes e representam uma fonte importante de alimentação da população. Os resultados das análises das espécies vegetais avaliadas permitiram detectar a presença de $\mathrm{Pb}$ com valores de até $118,2 \mathrm{mg} / \mathrm{kg}$, superando amplamente o valor limite estabelecido pela OMS para $\mathrm{Pb}$ em alimentos vegetais.

As concentrações de cádmio apresentaram um valor máximo de $7,39 \mathrm{mg} / \mathrm{kg}$, superando amplamente o valor recomendado para $\mathrm{Cd}$ pela OMS de $0,05 \mathrm{mg} / \mathrm{kg}$ para alimentos vegetais.

Observou-se que existe uma diferenciada tendência na absorção dos contaminantes provenientes do solo em frutas e ervas, além das gramíneas, condição que é influenciada pela susceptibilidade e pela específica afinidade aos metais de cada espécie vegetal.

As análises realizadas em alimentos vegetais cultivados em solos de quintais de Oliveira dos Campinhos (localidade utilizada como área de referência), Rua Rui Barbosa e Sacramento, expõem diferenças entre os conteúdos de $\mathrm{Pb}$ e $\mathrm{Cd}$ nas espécies avaliadas, confirmando uma "anormalidade" nos teores dos metais detectados nestes vegetais em Santo Amaro.

As concentrações dos contaminantes de interesse detectadas no presente trabalho confirmam a persistência da contaminação em espécies vegetais da área de estudo, correspondendo-se aos valores expostos por Costa no ano de 2001 em alimentos vegetais e gramíneas da área atingida pela contaminação.

Os fatores de transferência solo-planta para chumbo e cádmio determinados no total das espécies vegetais analisadas podem ser considerados como baixos considerando as altas concentrações dos contaminantes no solo (caso do $\mathrm{Pb}$ ) onde estas espécies se desenvolvem e os valores típicos reportados na literatura (para $\mathrm{Pb}$ e $\mathrm{Cd}$ ).

Os valores dos $\mathrm{FT}_{\text {solo-planta }}$ indicam que o conteúdo dos contaminantes no solo não corresponde à única variável que influencia a presença destes elementos nos vegetais. Os valores de $\mathrm{FT}_{\text {solo-planta }}$ para $\mathrm{Cd}$ apresentaram-se maiores em comparação aos $\mathrm{FT}_{\text {solo-planta }}$ para $\mathrm{Pb}$ $(\mathrm{Cd}>\mathrm{Pb})$, sendo que o conteúdo no solo deste contaminante é menor que o teor de $\mathrm{Pb}$.

Embora os valores dos $\mathrm{FT}_{\text {solo-planta }}$ sejam baixos, a presença de teores dos contaminantes de interesse na parte aérea e/ou comestível das espécies avaliadas expõe a transferência, absorção e translocação dos metais desde o solo para as raízes e posteriormente para a parte aérea das espécies. Esta condição indica que parte do total do conteúdo dos contaminantes no solo esta biologicamente disponível de forma específica para as espécies vegetais analisadas, podendo representar um risco para a população pelo consumo alimentar dos mesmos.

Por outro lado, $\mathrm{FT}_{\text {solo-planta }}$ baixos para os contaminantes avaliados podem indicar a alta capacidade do solo na retenção e acumulação de metais. Desta forma, pode se inferir que o solo atingido pela contaminação por metais em Santo Amaro apresenta uma alta capacidade na retenção dos contaminantes de interesse e somente uma fração do seu conteúdo total dos elementos no solo está disponível para as plantas.

Apesar de as espécies vegetais avaliadas apresentem mecanismos de absorção, distribuição, metabolismo e excreção diferenciados, os $\mathrm{FT}_{\text {solo-planta }}$ determinados permitem avaliar a contribuição dos conteúdos dos contaminantes de interesse presentes no solo que são transferidos para as plantas, além do potencial risco por consumo alimentar dos mesmos. Os resultados apresentados neste trabalho estão restritos às condições atuais do problema, podendo apresentar variações no tempo. É necessário determinar os $\mathrm{FT}_{\text {solo-planta }}$ para $\mathrm{Pb}$ e $\mathrm{Cd}$ em outras partes das espécies vegetais de estudo. Desta maneira 
será possível observar com maior detalhe os processos de absorção desde o solo, translocação e acumulação dos contaminantes de interesse nas espécies vegetais.

\section{AGRADECIMENTOS}

A realização deste trabalho foi possível graças ao apoio das equipes do Centro de pesquisas e desenvolvimento (CEPED), Laboratório em meio ambiente da UCSAL (LEMA), Laboratório de geotecnia ambiental da UFBA (GEOAMB), a população de Santo Amaro-BA e as instituições CAPES e Fundação Escola Politécnica.

\section{REFERÊNCIAS}

1. Adriano, D.C. Em Anais do International Symposium on Trace Elements in the Food Chain, Budapest, Hungria, 2006.

2. Efron, D.; De la Horra A.M.; Defrieri, R.L.; Fontanive, V.; Palma, R.M.; Commun. Soil Sci. Plant Anal. 2004, 35, 1309.

3. Baldrian, P. Em Soil Heavy Metals; Sherameti, I.; Varma, A., eds.; Springer-Verlag: Berlin Heidelberg, 2010.

4. Galán, H.E.; Romero, B.A. Em Resumo da Conferencia de Contaminación de Suelos por Metales Pesados (MACLA 10), Barcelona, Espanha, 2008.

5. Kabata-Pendias, A.; Pendias, H. Trace Elements in Soils and Plants, $3^{\text {th }}$ ed., CRC press: Florida, 2001

6. Zeng L.S.; Liao, M.; Chen, C.L.; Huang, C.Y.; Ecotoxicol. Environ. Saf. 2007, 67, 67.

7. Voutsa, D.; Grimanis, A.; Samara, C.; Enviro. Pollut. 1996, 94, 325.

8. Ginoccio, R.; Narváez, J.; Rev. Chil. Hist. Nat. 2002, 75, 603.

9. Prieto, M.J.; Ramírez, G,A,C.; Gutiérrez, R, D.; Garcia, P. F.; Trop. Subtrop. Agroecosyt. 2009, 10, 29.
10. Intawongse, M.; Dean, R.D.; Food. Addit. Contam. 2006, 23, 36.

11. Chopin, E.I.B.; Alloway, B.J.; Water. Air. Soil. Pollut. 2007, 182, 245.

12. Chary, N.S; Kamala, C.T; Raj Suman Samuel, D.; Ecotoxicol. Environ. Saf. 2007, 69, 513.

13. Anselmo, F. L. A.; Jones, M. C. Em Anais do XXV Encontro Nacional de Engenharia de Produção, Porto Alegre, 2005.

14. Alloway, B.J. Heavy Metals in Soils. $2^{\text {th }}$ ed., Blackie Academic \& Professional: London, 1995.

15. Orihuela, D. L.; Hernandez, J. C.; Weiland C. M.; Moreno, C. M.; Agrícola Vergel, 2008, 313, 35.

16. Kachenko,A.G.; Sing, B.; Water. Air. Soil. Pollut. 2006, 169, 101.

17. Machado, S. L.; Ribeiro, L. D.; Kiperstok, A.; Botelho, M. A. B.; Carvalho, M. F.; Eng. Sanit. Ambient. 2004, 9, 140.

18. Ribeiro, L. D.; Machado, S. L.; Kiperstok, A.; Baker, F. R.; Em Anais do $V$ Congresso Brasileiro de Geotecnia Ambiental REGEO, Porto Alegre, 2003.

19. Anjos, J. A. S.; Tese de Doutorado, Universidade de São Paulo, Brasil, 2003.

20. Rabelo, T. S.; Dissertação de Mestrado, Universidade Federal da Bahia, Brasil, 2010.

21. Brasil. Conselho Nacional do Meio Ambiente. Resolução $\mathrm{N}^{\circ} 420$, de 28/12/09. Diário Oficial da União, 30/12/2009.

22. Cunha, P.S.P; Araújo, P.S.P.; Laudo Pericial, Bahia, 2001.

23. Kabata Pendias, A.; Mukherjee, B.A.; Trace Elements From Soil to Human. Springer: New York, 2007.

24. Costa, A. C. A.; Dissertação de Mestrado, Universidade Federal da Bahia. Brasil, 2001

25. Finster, M.E.; Gray, K.A.; Binns, H.J.; Sci. Total Environ. 2003, 230, 245. 